\title{
PERSPEKTIF MASYARAKAT TERHADAP PROGRAM KEMITRAAN KEHUTANAN SEBAGAI SOLUSI KONFLIK TENURIAL DI KESATUAN PENGELOLAAN HUTAN LINDUNG RINJANI BARAT
}

\section{(Community Perspective to Forestry Partnership Programme as Land Tenure Conflict Solution in Protected Forest Management Unit Rinjani Barat)}

\author{
GISTA M. RUKMINDA ${ }^{1 *}$, RINEKSO SOEKMADI ${ }^{2)}$ DAN SOERYO ADIWIBOWO ${ }^{3)}$ \\ 1) Program Studi Magister Pengelolaan Sumberdaya Alam dan Lingkungan, Sekolah Pasca Sarjana Institut Pertanian \\ Bogor, Kampus IPB Baranangsiang, Bogor, Indonesia 16129 \\ 2) Departemen Konservasi Sumberdaya Hutan \& Ekowisata, Fakultas Kehutanan Institut Pertanian Bogor, Kampus \\ Darmaga, Bogor, Indonesia 16680 \\ 3) Departemen Sains Komunikasi dan Pengembangan Masyarakat, Fakultas Ekologi Manusia, Institut Pertanian Bogor,
} Kampus Dramaga, Bogor 16680

*Email: gista.rukminda@gmail.com

Diterima 13 Agustus 2019 / Disetujui 17 Februari 2020

\begin{abstract}
As the important part of good forest governance improvement, Indonesia actively promote Forest Management Unit (Kesatuan Pengelolaan Hutan or KPH) and Forestry Partnership program (one type of Social Forestry). Both are relatively new institution and key elements of forest governance reform. One of KPH model in Indonesia is Protected Forest Management Rinjani Barat Unit, Lombok Island, or in short KPHL RB which was the best KPH in 2015 through its Forestry Partnership programme achievement facing tenurial conflict in their forest area. This research aim to analyze how the success and failure of the Forestry Partnership programme carried out by KPHL RB from the perspective of organizational management and local community in particular. This research method uses both qualitative and quantitative approach which were analized descriptively. The results of the study show that, first, through the Forestry Partnership Programme the intensity of tenure conflict between KPHL $R B$ and local community significantly reduced up to 80 percent (indicated by changes from red to yellow color in the map). The Forestry Partnership Agreement between KPHL RB and local community that addressed the legitimacy of (bundle) right of the local community to access the forest area, are the important factor that significantly reduce the conflict. Secondly, most of the respondents perceived the Agreement as legitimate window for secure access to protected forest. Although the welfare of local community is not yet increase significantly, however, but the local community now have a security of tenure which is an important foundation for sustainable livelihood security. From the perspective of social institution, it can be concluded that the Forest Partnership is a significant success program both for the KPHL RB as well as the local community. However, the future of this program sustainability is under question as the prime wheel of the program that is the KPHL RB, is under weak position.
\end{abstract}

Keywords: access right, Forest Management Unit (KPHL RB), forestry partnership, tenure conflict

\section{ABSTRAK}

Sebagai bagian penting dari perbaikan tata kelola hutan, Indonesia kini tengah giat mempromosikan dua institusi baru: Kesatuan Pengelolaan Hutan (KPH) dan program Kemitraan Kehutanan (salah satu tipe dari Perhutanan Sosial). Salah satu KPH model di Indonesia adalah KPH Lindung Rinjani Barat atau KPHL RB yang merupakan KPH terbaik pada tahun 2015 melalui pencapaian program Kemitraan Kehutanan sebagai solusi konflik tenurial di wilayah kerja mereka. Penelitian bertujuan untuk menganalisis bagaimana keberhasilan atau kegagalan program Kemitraan Kehutanan dilihat dari perspektif manajemen organisasi dan pandangan masyarakat setempat. Metode penelitian menggunakan pendekatan kualitatif dan kuantitatif yang dianalisis secara deskriptif. Hasil penelitian menunjukkan bahwa, pertama, melalui program Kemitraan Kehutanan intensitas konflik tenurial antara KPHL RB dan warga lokal berkurang sebesar 80 persen (di dalam peta diindikasikan oleh berubahnya warna merah menjadi kuning). Perjanjian Kemitraan antara KPHL RB dan warga lokal yang melegitimasi (himpunan) hak akses warga di dalam kawasan hutan, menjadi faktor penentu turunnya intensitas konflik tenurial. Kedua, sebagian besar responden (yang merupakan representasi warga lokal) menyatakan bahwa berkat perjanjian Kemitraan mereka memiliki akses yang legitimate ke dalam kawasan hutan. Walau peningkatan kesejahteraan warga lokal belum tampak signifikan sebagai akibat Kemitraan Kehutanan, namun warga kini memiliki security of tenure (keamanan tenurial) yang menjadi landasan penting bagi sustainable livelihood security (keamanan nafkah yang berkelanjutan). Dari perspektif institusi, dapat disimpulkan bahwa Kemitraan Kehutanan merupakan program yang terbilang sukses baik di mata komunitas sekitar maupun KPHL RB. Namun demikian, masa depan keberlanjutan program ini menjadi pertanyaan ketika motor program ini, yakni KPHL RB, saat ini berada dalam kondisi yang lemah. 


\section{PENDAHULUAN}

Berdasarkan data KLHK (2018), Indonesia mengalokasikan sekitar 63\% atau seluas 120,6 juta hektar daratannya sebagai Kawasan Hutan sedangkan sisanya merupakan Areal Penggunaan Lain. Namun demikian, KLHK (2013) memperkirakan seluas 17,6 juta hektar - 24,4 juta hektar kawasan hutan terjadi konflik di antaranya berupa overlap klaim hutan negara dan klaim masyarakat adat maupun masyarakat lokal, pengembangan desa/kampung serta adanya izin sektor lain yang pada prakteknya terletak dalam kawasan hutan. Hal ini didukung hasil kajian World Bank (2014) bahwa hampir 25 juta hektar kawasan hutan terjadi konflik, terutama karena kompetisi klaim lahan dan isu tata kelola.

De Koning et al. (2008) dalam Fisher et al. (2017) menyatakan bahwa jumlah dan intensitas konflik hutan dan lahan terjadi sangat parah di negara berkembang yang dianugerahi dengan kekayaan sumber daya alam dan keanekaragaman budaya namun terganggu oleh tata kelola yang lemah dan tekanan ekonomi yang mengeksploitasi sumber daya. Gritten dan Mula Yudego (2011) dalam Fisher et al. (2017) menambahkan bahwa Indonesia adalah contoh utama negara-negara dimaksud. Sementara itu, menurut KPK (2013) bahwa akar dari persoalan konflik di kawasan hutan dapat dipadatkan dalam kalimat "tidak adanya kepastian penguasaan (tenurial security)". Sehingga kehadiran de facto pengelola kawasan hutan (forest manager) di lapangan (on site) sangat dibutuhkan. Menurut KLHK (2014) dalam Hernowo dan Ekawati (2014), pembentukan Kesatuan Pengelolaan Hutan (KPH) berperan penting dan strategis mengelola kawasan hutan negara di tingkat tapak. Pembentukan KPH dapat pula dilihat dari kegagalan Pemerintah dalam mengelola kawasan hutan karena ketidakhadiran pengelola pada tingkat tapak.

Salah satu KPH model di Indonesia adalah KPH Lindung Rinjani Barat atau KPHL RB. Dinas LHK NTB (2017) menyatakan bahwa pada tahun 2015 KPHL RB pernah mendapatkan penghargaan sebagai KPH terbaik se-Indonesia karena dianggap mampu menyelesaikan konflik tenurial di kawasannya melalui kemitraan kehutanan. Menurut Bae et al. (2014) bahwa berdasarkan data KPHL RB terdapat \pm 24.000 keluarga menempati lebih dari 18.000 hektar kawasan hutan negara dari total 40.000 hektar wilayah kelola KPHL RB. Sebagian dari mereka mencari kepemilikan formal (sertifikat) atas lahan kawasan hutan sementara sebagian lainnya membuka lahan hutan untuk keuntungan ekonomi jangka pendek. Di sisi lain, sebagai organisasi di tingkat tapak, KPHL RB memahami penyebab konflik yang selama ini terjadi di wilayah kelolanya yaitu akses masyarakat untuk memanfaatkan hutan. Dengan otonomi yang memadai untuk mengambil keputusan, KPHL RB dengan cerdas menawarkan skema Kemitraan Kehutanan sebagai bagian dari Perhutanan Sosial untuk menyelesaikan konflik yang ada. Berliani (2015) dalam
Riski (2016) menegaskan bahwa skema kemitraan kehutanan di KPHL RB menjadi contoh penyelesaian konflik yang baik untuk daerah lain. Sehingga perlu dikaji, bagaimana proses pelaksanaan Kemitraan Kehutanan di KPHL RB terutama terkait dengan aspek tenurial?

Peraturan Menteri LHK No. P.83 Tahun 2016 mewajibkan pengelola hutan (termasuk KPH) atau pemegang izin melaksanakan pemberdayaan masyarakat setempat melalui kemitraan kehutanan. Melalui skema kemitraan antara masyarakat dan $\mathrm{KPH}$, bukan saja menyelesaikan persoalan tenurial namun juga diharapkan menjadi solusi bagi masyarakat untuk meningkatkan kesejahteraannya karena masyarakat dapat memanfaatkan hasil hutan dengan tetap menjunjung prinsip pengelolaan hutan lestari. Pertanyaan selanjutnya adalah, setelah masyarakat mitra mendapat legalitas dalam mengelola dan memanfaatkan hutan, apakah kondisi lingkungan membaik dan kesejahteraan masyarakat meningkat? Bagaimana capaian keberhasilan atau kegagalan Kemitraan Kehutanan di KPHL RB dari perspektif pengelola dan masyarakat setempat?

Berangkat dari latar belakang dan rumusan masalah di atas, tujuan penelitian ini adalah (1) Mengkaji proses pelaksanaan kemitraan kehutanan di KPHL RB terutama terkait dengan aspek tenurial; serta (2) Menganalisis perspektif pengelola dan masyarakat setempat terhadap keberhasilan atau kegagalan kemitraan kehutanan di KPHL RB.

\section{METODE PENELITIAN}

Penelitian dilakukan di KPHL RB dengan memfokuskan kajian pada kelompok tani anggota Koperasi Serba Usaha Kompak Sejahtera (KSU KS) di Desa Rempek, Kecamatan Gangga, Kabupaten Lombok Utara yang telah bermitra dengan KPHL RB (Gambar 1). Penentuan lokasi penelitian dilakukan secara purposive dengan pertimbangan bahwa pada tahun 2015 KPHL RB ini mendapatkan penghargaan sebagai KPH terbaik seIndonesia melalui skema Kemitraan Kehutanan sebagai solusi konflik dengan masyarakat setempat. Pengambilan data primer dilakukan pada Bulan Mei 2018.

Data yang dibutuhkan pada penelitian ini dikumpulkan melalui kuesioner, wawancara mendalam (pedoman), studi pustaka (peraturan perundangan, jurnal ilmiah, laporan, dan sebagainya), serta observasi lapangan yang dilakukan dengan cara pengamatan dan pencatatan secara sistematis dan dianalisis dengan metode yang secara lengkap disajikan pada Tabel 1.

Selain melalui observasi lapang dan studi pustaka, data dikumpulkan melalui survey kuesioner pada responden dan wawancara mendalam pada narasumber. Responden dalam penelitian ini adalah anggota KSU KS yang bermitra dengan KPHL RB dalam skema kemitraan kehutanan. Pemilihan responden dilakukan dengan 
teknik simple random sampling sebanyak 30 responden dari 381 orang anggota KSU KS. Nenurut Gay (1976) dalam Suryapriadi (2013) bahwa untuk penelitian deskriptif dapat diwakili oleh $10 \%$ dari populasi dan untuk penelitian korelasi dapat diwakili oleh 30 subyek. Sampel responden dalam penelitian ini kurang dari target $10 \%$ populasi karena keterbatasan peneliti saat di lapangan (sedang mengandung/hamil), mempertimbangkan jawaban dari responden yang cenderung homogen serta didukung/diperkuat data dan informasi dari para narasumber yang relatif cukup menjawab tujuan penelitian. Wawancara mendalam dengan pedoman wawancara dilakukan kepada narasumber yang dipilih secara purposive terdiri dari 2 orang perwakilan tokoh masyarakat, 2 orang perwakilan Tim 9, Ketua KSU KS, 1 orang perwakilan pengelola KPHL RB, Kepala Dinas Lingkungan Hidup dan Kehutanan Provinsi Nusa Tenggara Barat (Kepala KPHL RB periode tahun 2009 - 2017), Direktur LSM Samanta beserta 1 orang staf.

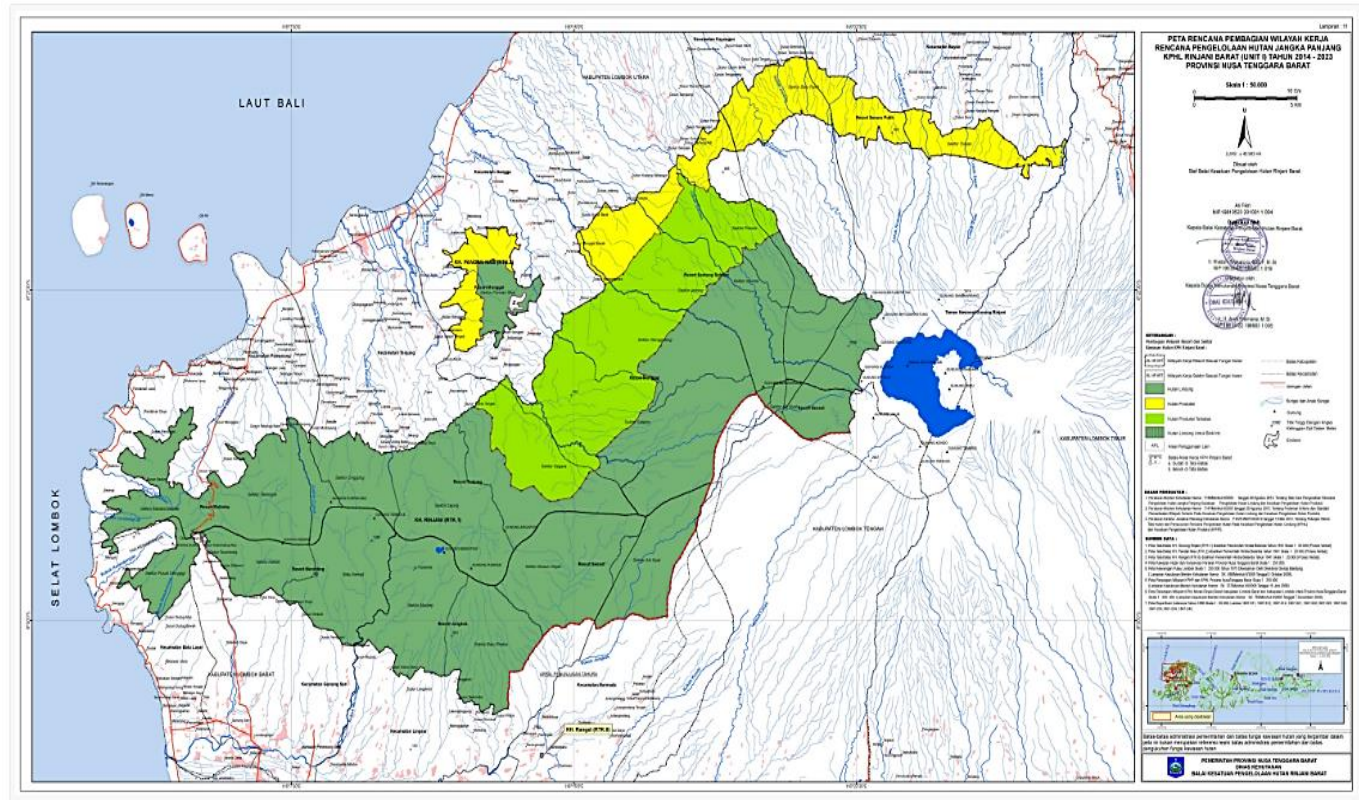

Gambar 1 Lokasi Penelitian (KPHL RB 2014)

Tabel 1 Prosedur pengumpulan dan analisis data

\begin{tabular}{|c|c|c|c|c|c|}
\hline Komponen tujuan & Aspek & Sumber & $\begin{array}{c}\text { Metode } \\
\text { pengumpulan } \\
\text { data }\end{array}$ & $\begin{array}{l}\text { Metode } \\
\text { analisis } \\
\text { data }\end{array}$ & Output \\
\hline $\begin{array}{l}\text { Mengkaji proses } \\
\text { pelaksanaan } \\
\text { Kemitraan } \\
\text { Kehutanan di KPHL } \\
\text { RB terkait aspek } \\
\text { tenurial }\end{array}$ & $\begin{array}{l}\text { Proses } \\
\text { Kemitraan } \\
\text { Kehutaann } \\
\text { terbangun }\end{array}$ & $\begin{array}{ll}\text { - } & \text { Responden } \\
\text { - } & \text { Narasumber } \\
\text { (perwakilan tokoh } \\
\text { masyarakat, tim 9, } \\
\text { ketua KSU KS, } \\
\text { pengelola KPHL RB, } \\
\text { Kadishut LHK NTB, } \\
\text { Direktur LSM } \\
\text { Samanta dan staf) }\end{array}$ & $\begin{array}{l}\text { - Kuesioner } \\
\text { - Wawancara } \\
\text { mendalam } \\
\text { - Observasi } \\
\text { lapang } \\
\text { - Studi } \\
\text { pustaka }\end{array}$ & Deskriptif & $\begin{array}{l}\text { Skema dan potret } \\
\text { pelaksanaan } \\
\text { Kemitraan } \\
\text { Kehutanan di } \\
\text { KPHL RB }\end{array}$ \\
\hline $\begin{array}{l}\text { Menganalisis } \\
\text { keberhasilan atau } \\
\text { kegagalan kemitraan } \\
\text { di KPHL RB dari } \\
\text { perspektif pengelola } \\
\text { KPHL RB dan } \\
\text { masyarakat }\end{array}$ & $\begin{array}{l}\text { - Perspektif } \\
\text { KPHL RB } \\
\text { - Perspektif } \\
\text { masyarakat } \\
\text { setempat }\end{array}$ & 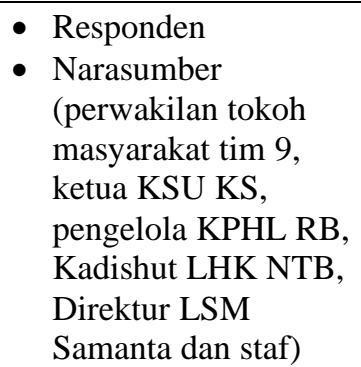 & $\begin{array}{l}\text { - Kuesioner } \\
\text { - Wawancara } \\
\text { mendalam } \\
\text { - Observasi } \\
\text { lapang } \\
\text { - Studi } \\
\text { pustaka }\end{array}$ & Deskriptif & $\begin{array}{l}\text { Evaluasi } \\
\text { keberhasilan/ } \\
\text { kegagalan } \\
\text { kemitraan } \\
\text { berdasarkan } \\
\text { perspektif KPHL } \\
\text { RB dan masyarakat } \\
\text { setempat }\end{array}$ \\
\hline
\end{tabular}




\section{HASIL DAN PEMBAHASAN}

\section{Proses Kemitraan Kehutanan Terbangun di KPHL Rinjani Barat}

Perjalanan program Kemitraan Kehutanan di RTK I Gunung Rinjani, KPHL RB tidaklah mudah. Konflik tenurial yang terjadi menjadi aspek utama yang perlu diperhatikan dan tidak terlepas dari sejarah pengelolaan KPHL RB. Riggs et al. (2016) menyatakan bahwa konflik tenurial di wilayah tersebut telah terjadi lebih dari tiga dekade dan mencontohkan berbagai dimensi reforma agraria di Indonesia. Sementara itu, Mukarom (2013) menyebutkan bahwa tingkat ekskalasi konflik tenurial yang terjadi di KPHL RB dibagi menjadi tiga kategori yaitu tinggi, sedang dan rendah. Tingkat eskalasi konflik pada ketegori tinggi ditandai oleh adanya sertifikat tanah milik di dalam kawasan hutan serta adanya pemukiman. Kategori yang lebih rendah ditandai oleh penggarapan/pengelolaan lahan kawasan hutan nonprogram. Tingkat eskalasi konflik di KPHL RB diilustrasikan pada Gambar 2.

Desa Rempek merupakan desa yang berbatasan langsung dengan kawasan hutan Register Tanah Kehutanan (RTK) I Gunung Rinjani - KPHL RB dan desa tersebut dikategorikan memiliki tingkat eskalasi konflik tinggi karena terdapat sertifikat hak milik dan permukiman di dalam kawasan hutan. Dari 17 dusun yang ada di desa tersebut, tiga di antaranya berada di dalam kawasan hutan. Saat ini terdapat sekitar $160 \mathrm{KK}$ yang bermukim di kawasan HP bersertifikat Prona sejumlah 84 persil. Adapun di kawasan HP (ex Government Ground) saat ini terdapat $\pm 300 \mathrm{KK}$ yang bermukim dan mayoritas menuntut agar tempat tinggal dan lahan garapan mereka untuk disertifikatkan juga. Selain itu, sebagian lahan garapan warga Rempek juga berada di kawasan hutan. Warga yang menggarap lahan di HPT (eks areal HPH PT ART) berjumlah sekitar 600 KK.

Sementara itu, KLHK berupaya memperbaiki tata kelola kehutanan melalui pembentukan KPH di seluruh kawasan hutan Indonesia. Pembentukan KPH di Provinsi NTB dilaksanakan pada periode tahun 2006 hingga 2008, adapun KPHL RB sebagai salah satu KPH Model Nasional ditetapkan pada tahun 2009 sesuai SK. 785/Menhut-II/2009 dengan wilayah kerja seluas \pm 40.983 Ha. Pada awalnya bentuk organisasi KPHL RB adalah Satuan Kerja Perangkat Daerah (SKPD) sesuai Peraturan Daerah Provinsi NTB Nomor 13 Tahun 2014 namun sejak tahun 2016 KPH di NTB turun statusnya sebagai Unit Pelaksana Teknis Dinas sesuai Peraturan Gubernur NTB Nomor 53 Tahun 2016.

Saat KPHL RB hadir dengan membawa wajah baru pemerintah melalui berbagai upaya pendekatan yang dilakukan secara kolaboratif, persuasive dan bottom-up, akhirnya konflik di Rempek mulai mereda. Kepercayaan masyarakat terhadap KPHL RB pun semakin tumbuh dengan berbagai terobosan yang dilakukan Kepala KPHL RB beserta para pegawainya, di antaranya yaitu upaya reboisasi hutan melalui penyediaan bibit tanaman Multipurpose Tree Species (MPTS) yang dibutuhkan masyarakat. Meskipun tidak sesuai RAB, namun melalui praktek diskresinya, Kepala KPHL RB berusaha mengakomodir bibit unggul tanaman MPTS yang diambil dari berbagai anggaran termasuk rapat-rapat bahkan masyarakat dilibatkan dalam proses pencairan dananya (transparan).

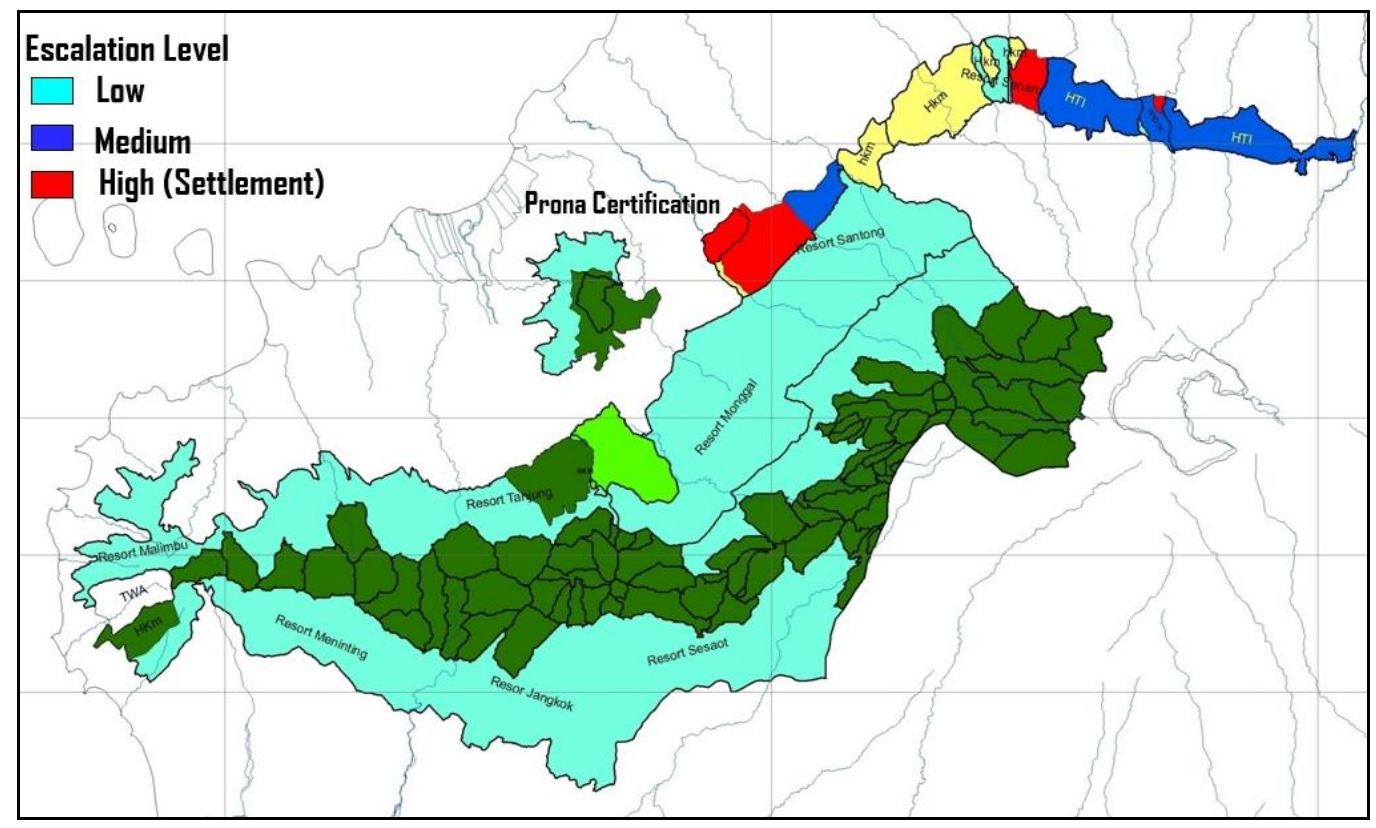

Gambar 2 Tingkat eskalasi konflik di KPHL RB (Mukarom 2013) 
Dari tiga opsi penyelesaian konflik di kawasan hutan yaitu mediasi, perhutanan sosial atau penegakan hukum, KPHL RB menawarkan skema perhutanan sosial (PS) karena sebagai organisasi di tingkat tapak, KPHL RB memahami salah satu penyebab utama konflik yang selama ini terjadi di wilayah kelolanya yaitu akses masyarakat untuk memanfaatkan kawasan hutan. Tahapan pertama yang dilakukan yaitu identifikasi skema PS yang sesuai dengan potensi dan kondisi sosial budaya masyarakat setempat. Setelah identifikasi, KPHL RB dibantu dengan LSM Samanta melakukan sosialisasi skema PS beserta hak dan kewajiban pemegang izin PS. Selanjutnya, KPHL RB membantu masyarakat dalam memilih skema PS dan menyusun usulan sesuai skema yang dipilih.

Saat sosialisasi PS dilakukan, KPHL RB menggulirkan isu kesejahteraan dan kelestarian hutan untuk menarik minat masyarakat. Namun dari skema PS yang ditawarkan, ternyata Kemitraan Kehutanan yang diterima dengan baik oleh mayoritas warga Rempek karena dianggap paling relevan dengan karakteristik dan kebutuhan masyarakat, paling praktis birokrasinya, terdapat kesetaraan peran, adanya bagi hasil, keanggotaan yang dapat diwariskan dan berbagai manfaat lainnya. Hal ini dibuktikan dengan semakin bertambahnya jumlah masyarakat Rempek yang bergabung dengan program kemitraan kehutanan melalui keanggotaan Koperasi Serba Usaha Kompak Sejahtera (KSU KS) yang pada awalnya (tahun 2013) berjumlah 67 orang, pada tahun 2018 menjadi 381 orang. Kesepakatan Kerjasama antara KPHL RB dengan KSU KS berhasil ditandatangani pada tahun 2014 yaitu setahun setelah peraturan Kemitraan Kehutanan (Peraturan Menteri LHK No. 39 Tahun 2013) disosialisasikan meskipun kemudian direvisi dan dilengkapi pada tahun 2018 karena dinamika peraturan yang melandasinya (Peraturan Menteri LHK No. 83 Tahun 2016).

Dari total sekitar $2.000 \mathrm{Ha}$ luas calon areal Kemitraan Kehutanan di HP dan HPT, yang sudah sepakat dituangkan dalam NKK adalah seluas 623,25 Ha. KPHL RB dan masyarakat sepakat bahwa Kemitraan Kehutanan rencananya akan dilakukan dalam tiga tahap yaitu pertama di HPT seluas 623,25 Ha, tahap kedua di Gegumuk atau buffer zone, dan sisanya tahap ketiga adalah di HP (prona dan sekitarnya). Areal Kemitraan Kehutanan tahap pertama merupakan lahan produktif masyarakat dan daerah konflik eskalasi sedang (penggunaan lahan non program). Mereka merupakan petani yang membutuhkan akses, jaminan produksi dan pemasaran. Mayoritas petani yang menggarap di HPT juga bermukim di HP (areal konflik eskalasi tinggi). KPHL RB dan masyarakat sepakat untuk terlebih dahulu menyukseskan program Kemitraan Kehutanan di HPT karena jika program tersebut berhasil maka masyarakat lainnya tanpa diajakn pun akan menawarkan diri untuk bergabung.

\section{Perspektif Pengelola KPHL RB dan Masyarakat Setempat terhadap Kemitraan Kehutanan di KPHL RB}

Perspektif menurut KBBI versi daring (2018) adalah 1) cara melukiskan suatu benda pada permukaan yang mendatar sebagaimana yang terlihat oleh mata dengan tiga dimensi (panjang, lebar dan tingginya); 2) sudut pandang, pandangan. Perspektif pengelola KPHL RB dan masyarakat setempat dimaksudkan sebagai sudut pandang atau pandangan KPHL RB dan masyarakat yang menjadi mitra KPHL RB terhadap penyebab keberhasilan atau kegagalan Kemitraan Kehutanan di KPHL RB terutama terkait dengan aspek tenurial dan konflik.

\section{a. Perspektif Pengelola KPHL Rinjani Barat}

Menurut pengelola KPHL RB, Rempek adalah salah satu contoh konflik tenurial selama 34 tahun dari yang warnanya merah sekarang sudah menjadi kuning. Rempek belum bisa dikatakan hijau karena hasilnya belum bisa dirasakan. Hasil bukan hanya yang disetor dalam bentuk uang namun juga masyarakat harus bisa berdiri di kaki sendiri, dapat menyadarkan orang lain dan memberikan dampak secara luas ke desa di sekitarnya.

"Perkembangan Kemitraan Kehutanan di RTK I Gunung Rinjani saat ini masih sampai pada ketenangan, kenyamanan, dan keamanan masyarakat mengakses hutan", kata TGY, sebagai perwakilan pengelola KPHL RB.

Menurut KPHL RB, target KPH saat ini adalah terciptanya keamanan warga dalam mengelola dan memanfaatkan kawasan (security of tenure). Jika akses pemanfaatan dan pengelolaan kawasan oleh warga legitimate, maka kawasan hutan akan lebih mudah diawasi dan dikendalikan. Produk hasil hutan akan tercipta kemudian.

"KPHL RB mencoba menyelesaikan masalah dengan masalah. Munculkan masalah baru yang masyarakat tertarik. Namun, maukah, mampukah KPHL RB dan bagaimana caranya? Bukanlah hal yang mudah mempertahankan komitmen Kemitraan Kehutanan di lapangan", tutup TGY.

Pengelola KPHL RB menyadari bahwa setelah Naskah Kesepakatan Kerjasama (NKK) ditandatangani maka akan ada pekerjaan rumah yang menungggu untuk dibuktikan oleh KPHL RB yaitu tercapainya kesejahteraan masyarakat dan kelestarian hutan. Pengembangkan kemitraan kehutanan dibutuhkan komitmen dari semua pihak. RPHJP KPH harus sinkron dengan kebijakan pusat dan daerah, ketersediaan anggaran, dan jaring kerja stakeholder merupakan faktor penentu. Konsep awal KPH sesungguhnya luar biasa dan cocok dikembangkan di tingkat tapak (separuh pemerintah dan separuh enterpreneur), namun peraturan yang ada belum dapat memfasilitasi hal-hal tersebut. Teknologi dan kapasitas produksi pabrik KPH masih sangat rendah sedangkan kebutuhan pasar sangat tinggi. 
Terobosan (out of the box) harus dilakukan karena sulit jika hanya mengandalkan anggaran pemerintah.

Selanjutnya, menurut pengelola bahwa tercapainya security of access dan security of tenure sebagai landasan penting bagi security of sustainable livelihood di KPHL $\mathrm{RB}$, salah satunya karena faktor leadership yang sesuai (kompeten) dengan kebutuhan KPH. Leadership yang kurang mendukung mengakibatkan terjadinya penurunan prestasi KPHL RB. Komitmen pengembangan kemitraan kehutanan dengan demikian amat tergantung pada leadership dan kebijakannya baik pada tataran KPHL RB, pada tataran Dinas LHK Provinsi dan juga pada tataran Kementerian LHK di Pusat.

\section{b. Perspektif Warga Mitra}

\section{b.1 Penataan masalah tenurial}

Berdasarkan Tabel 2, bahwa sebesar 63,33\% responden menjawab dengan bergabung Kemitraan Kehutanan, mereka mendapatkan kemudahan, keamanan dan kenyamanan dalam mengakses hutan dan hasilnya. Hal tersebut jauh lebih baik dibandingkan sebelum bergabung karena jika ada kera jatuh saja mereka kira itu adalah petugas patroli. Selain merasa aman karena tidak dikejar-kejar petugas juga aman dari gangguan pihak tertentu. Petugas KPH juga bisa dihubungi kapan saja jika ada kejadian di lapangan. Intinya warga mitra merasa mendapatkan pengakuan dan perlindungan. Lelah bekerja pun hilang karena tidak ada beban.

Bagi 16,67 \% reponden yang menjawab sama saja karena dari dulu mereka tidak merasa bersalah mengelola hutan asalkan tidak menebang kayu, merasa tidak bersalah karena belum mengerti status kawasan hutan, serta karena merupakan penggarap baru sehingga tidak merasakan pengalaman penggarap lainnya. Selain itu, mereka beranggapan bahwa Kemitraan Kehutanan belum dapat dirasakan hasilnya karena Surat Ijin Menggarap (SIM) belum keluar dan warga masih menjual Hasil Hutan Bukan Kayu ke pengepul, bukan melalui koperasi.

Dari uraian di atas, bahwa secara materi, keberhasilan kemitraan belum dapat terukur. Namun sudah berhasil dalam segi kenyamanan masyarakat bercocok tanam di kawasan hutan. Keberhasilan yang kedua yaitu dalam hal keamanan lahan dan tanamannya dari pencuri maupun illegal logger. Kemitraan Kehutanan membuat masyarakat dapat dengan mudah dan bisa kapan saja melaporkan kejadian apapun di lahan garapan mereka kepada KPHL RB. Antar penggarap tidak akan mengganggu atau mengambil lahan orang lain karena kejelasan batas lahan garapan dalam peta rincik sehingga tidak menimbulkan konflik. Hal ini mengilustrasikan salah satu macam penguasaan sumber daya menurut kumpulan hak menurut Schlager dan Ostrom (1992) yaitu Kemitraan Kehutanan menjamin hak eksklusi (mengeluarkan) pihak yang tidak berhak atas sumber daya. Masyarakat kini dapat menerima bantuan bibit tanaman dari pemerintah, dahulu sebelum bermitra hal tersebut masih dianggap illegal karena tidak ada dasar untuk meminta bantuan dari pemerintah. Namun demikian, terkait komitmen tindak lanjut NKK Kemitraan Kehutanan, belakangan ini sering didengar oleh masyarakat dalam diskusi tentang statement dari KPHL RB terkait anggaran.

"Kalau KPH ada uang, kalau KPH ada dana. Lalu, pertanyaan masyarakat sederhana: sejauh mana komitmen pemerintah meluncurkan sebuah program dengan aturan-aturan yang ada, kenapa harus tetap ada pernyataan klasik tentang dana?", kata KI (perwakilan tokoh masyarakat Desa Rempek).

Menurut masyarakat, pernyataan tersebut bukan merupakan jawaban yang pas untuk diberikan dan hal tersebut berbeda dengan leadership KPHL RB sebelumnya. MM sebagai Kepala KPHL RB terdahulu memiliki prinsip untuk menghindari mengatakan "tidak" di daerah konflik. Cara menjaga kepercayaan masyarakat agar tidak kendur adalah melalui bukti dan transparansi.

\section{b. 2 Frekuensi dan intensitas konflik}

Menurut responden, Kemitraan Kehutanan mampu menghilangkan konflik meskipun belum 100\% karena makelar kasus seperti pengepul, pengacara dan politikus masih ada, apalagi di tahun pemilu, dan sayangnya masyarakat masih ada yang percaya. Makelar yang dimaksud adalah pihak yang menjanjikan dapat membantu masyarakat untuk sertifikasi lahan di kawasan hutan, terutama di sekitar Prona (kawasan HP). Menurut Savath et al. (2014) bahwa lahan bukan hanya aset mata pencaharian untuk tujuan ekonomi tetapi juga berkontribusi terhadap modal sosial sebagai penanda status sosial. Hidup di tanah yang tidak bersertifikat tidak hanya memiliki dampak ekonomi pada masyarakat tetapi juga mengubah hubungan mereka di dalam komunitas mereka dan dengan Pemerintah. Konflik di Rempek telah menciptakan ketegangan di dalam masyarakat dan perasaan ketidakadilan sehubungan dengan skema sertifikasi tanah Prona tahun 1984.

Tabel 2 Jumlah dan persentase responden menurut tingkat keamanan akses.

\begin{tabular}{llcc}
\hline No & Tingkat keamanan akses & Jumlah responden & Persentase $(\%)$ \\
\hline 1 & Sangat baik & 6 & 20,00 \\
2 & Lebih baik & 19 & 63,33 \\
3 & Sama saja & 5 & 16,67 \\
4 & Lebih buruk & 0 & 0,00 \\
5 & Sangat buruk & 0 & 0,00 \\
\hline & Total & 30 & 100 \\
\hline
\end{tabular}


Berdasarkan Tabel, sebesar $50,00 \%$ responden mengaku tidak tahu apakah konflik masih ada atau tidak, sebesar 33,33\% responden menjawab bahwa konflik di Rempek sudah tidak ada dan sebesar $16,67 \%$ responden menjawab bahwa konflik di sana masih ada. Menurut responden, konflik yang pernah terjadi adalah antara warga pendatang dengan warga asli Rempek, yaitu adanya penyerobotan lahan dan penebangan kayu oleh warga pendatang. Konflik lainnya yang pernah terjadi adalah warga dengan perusahaan kayu (PT ART), serta antara warga dengan instansi kehutanan, bahkan hingga masuk penjara. Namun responden mengaku sudah tidak mendengar konflik terutama dengan pihak instansi kehutanan semenjak ada KPHL RB.

Akses masyarakat Rempek terhadap kawasan hutan dimulai jauh sebelum KPHL RB terbentuk dan konflik tenurial yang terjadi di sana pun telah terjadi lebih dari tiga dekade. Setelah ada KPHL RB dan Kemitraan Kehutanan terbangun, akses masyarakat penggarap lahan di areal kemitraan menjadi legal. Dengan adanya pengakuan dan perlindungan tersebut berpengaruh terhadap ketenangan, kenyamanan, keamanan masyarakat dalam mengelola hutan dan akan berpengaruh terhadap partisipasi yang baik dari masyarakat dalam mencapai cita-cita bersama yaitu kesejahteraan masyarakat dan kelestarian hutan. Adapun kontrol terhadap pengelolaan areal kemitraan masih didominasi oleh KPHL RB, yaitu dengan pembatasan jenis tanaman yang boleh dan tidak boleh ditanam serta kegiatan apa yang boleh dan tidak boleh dilakukan. Sementara itu, untuk penentuan lokasi areal kemitraan dan persentase bagi hasil merupakan hasil kesepakatan bersama antara KPHL RB dengan koperasi KSU KS.

Sekumpulan hak yang dimiliki oleh para pihak akan menentukan posisinya dalam sumber daya, apakah dia sebagai pemilik, pemilik terikat, penyewa atapun pengguna (Schlager dan Ostrom 1992). Setelah bergabung dengan kemitraan, para penggarap di kawasan hutan sekarang mempunyai hak akses, hak pengelolaan, hak eksklusi bahkan hak pengalihan atas sumber daya. Sebagai catatan, bahwa yang dimaksud dengan hak pengalihan di kemitraan adalah keanggotaannya dapat diwariskan kepada anggota keluarga, bukan hak untuk menjual ke pihak lain. Hak pewarisan keanggotaan ini merupakan salah satu hal yang menarik dari Kemitraan Kehutanan, ketentuan ini tidak terdapat pada skema perhutanan sosial lainnya. Menurut Agrawal dan Ostrom
(2001), hak pengalihan kepada anggota keluarganya merupakan hak yang baik untuk menciptakan penggunaan sumber daya yang efisien serta dapat menjamin kelestarian dan mendorong peningkatan hasil. Hak pengalihan kepada anggota keluarga ini menghindari kekhawatiran pemanfaatan sumberdaya oleh pihak lain.

Menurut KLHK (2019), kunci sukses perhutanan sosial adalah a) penguatan kelembagaan dengan indikator terbentuknya koperasi/BUMDES; b) pengelolaan hutan dengan indikator meningkatnya tutupan lahan hutan; dan c) pengembangan usaha (rencana bisnis dan desa sentra produksi) dengan indikator peningkatan pendapatan dan penurunan kemiskinan. Bagi pengelola KPHL RB dan masyarakat mitra, kerjasama kemitraan dapat dikatakan berhasil pada tahap resolusi konflik tenurial, yaitu diakui dan dilindunginya akses masyarakat dalam mengelola kawasan hutan. Mustafa (2002) menyatakan bahwa tercapainya resolusi konflik pengelolaan kawasan hutan salah satunya ditandai dengan terbukanya ruang atau akses bagi komunitas lokal atau dibukanya ruang partisipasi yang mengarah pada perbaikan taraf hidup komunitas.

Adapun bagi masyarakat Rempek, keberhasilan ini dapat diukur dengan bertambahnya jumlah masyarakat yang bergabung dalam koperasi sebagai mitra KPHL RB. Artinya, dari ketiga kunci sukses perhutanan sosial yang telah disebutkan di awal, bahwa kemitraan di Rempek baru mencapai keberhasilan dalam hal penguatan kelembagaan yaitu terbentuknya koperasi KSU KS dan berkembangnya jumlah anggota. Adapun untuk indikator penutupan lahan dan pendapatan belum dapat terukur karena keterbatasan data, di antaranya yaitu tidak tersedianya citra satelit resolusi tinggi untuk penafsiran periodik serta perjanjian kerjasama yang masih relatif baru ditandatangani sehingga masih minim kegiatan. Sementara itu, jenjang kemitraan di Rempek berdasarkan Heidenem (2002) dalam Kuswidanti (2008) berada pada tahap coalition, yaitu dengan adanya NKK yang telah ditandatangani oleh perwakilan KPHL RB dan koperasi KSU KS (formal agreement), adanya keterlibatan aktif kedua belah pihak yang bermitra (all member involved in), adanya dukungan fisik dan non fisik maupun materil dan imateril (new resource) serta telah adanya ketentuan bagi hasil yang tertuang dalam perjanjian kerjasama sebagai bentuk kontribusi para pihak (joint budget).

Tabel 3 Konflik setelah ada Kemitraan Kehutanan

\begin{tabular}{llll} 
No & Keterangan & Jumlah & Persentase $(\%)$ \\
\hline 1 & Masih ada & 5 & 16,67 \\
2 & Tidak ada & 10 & 33,33 \\
3 & Tidak tahu & 15 & 50,00 \\
\hline Total & & 30 & 100 \\
\hline
\end{tabular}




\section{SIMPULAN}

Konflik tenurial merupakan latar belakang dibangunnya program Kemitraan Kehutanan di Rempek (RTK I Gunung Rinjani, KPHL RB). Rempek yang dahulu berwarna merah (terjadi konflik tinggi) kini bertransformasi ke warna kuning (konflik rendah) namun belum hijau karena tujuan utama dari Kemitraan Kehutanan ini yaitu kesejahteraan masyarakat dan kelestarian hutan belum dapat terukur. Bagi KPHL RB dan masyarakat mitra, kemitraan kehutanan dapat dikatakan berhasil pada tahap resolusi konflik tenurial yaitu diakui dan dilindunginya akses masyarakat dalam mengelola kawasan hutan. Tantangan yang masih dihadapi yaitu rendahnya orientasi bisnis (social enterpreneur) dan faktor leadership terutama dari pengelola KPHL RB. Strategi pengembangan Kemitraan Kehutanan lebih lanjut dibutuhkan untuk menyelesaikan tantangan tersebut.

\section{DAFTAR PUSTAKA}

Agrawal A, Ostrom E. 2001. Collective action, property rights, and decentralization in resource use in India and Nepal. Politics and society. 29 (4):485-514.

Bae JS, Kim C, Kim YS, Latifah S, Afifi M, Fisher LA, Lee SM, Kim I, Kang J, Kim R, Kim JS. 2014. Opportunities for Implementing REDD+ to Enhance Sustainable Forest Management and Improve Livelihoods in Lombok, NTB Indonesia. Bogor: CIFOR.

[Dinas LHK NTB] Dinas Lingkungan Hidup dan Kehutanan Provinsi Nusa Tenggara Barat. 2017. Resolusi konflik tenurial: belajar dari balai $\mathrm{KPH}$ Rinjani Barat Pelangan Tastura [Internet]. [diunduh 2017 September 7]. Tersedia pada: https://dislhk.ntbprov.go.id/2017/05/19/resolusikonflik-tenurial-belajar-dari-balai-kph-rinjani-baratpelangan-tastura/

Fisher LA, Kim YS, Latifah S, Mukarom M. 2017. Managing forest conflicts: perspective of Indonesia's forest management unit directors. Forest and Society. 1(1): 8-26.

Hernowo B, Ekawati S. 2014. Operasionalisasi Kesatuan Pengelolaan Hutan (KPH): Langkah Awal Menuju Kemandirian. Jakarta: Kanisius.

[KBBI] Kamus Besar Bahasa Indonesia versi daring. 2018. Pengertian perspektif. [Internet]. [diunduh 2017 September 7]. Tersedia pada: https://kbbi.web.id/perspektif

[Kemenkumham] Kementerian Hukum dan Hak Asasi Manusia. 2013. Peraturan Menteri Kehutanan Republik Indonesia Nomor P.39/Menhut-II/2013 tentang Pemberdayaan Masyarakat Setempat Melalui Kemitraan Kehutanan. Jakarta: Kementerian Hukum dan Hak Asasi Manusia Republik Indonesia.
[Kemenkumham] Kementerian Hukum dan Hak Asasi Manusia. 2016. Peraturan Menteri Lingkungan Hidup dan Kehutanan Republik Indonesia Nomor P.83/Menlhk/Setjen/Kum.1/2016 tentang Perhutanan Sosial. Jakarta: Kementerian Hukum dan Hak Asasi Manusia Republik Indonesia.

[KLHK] Kementerian Lingkungan Hidup dan Kehutanan. 2013. Data Eksekutif KPH. Jakarta: KLHK.

[KLHK] Kementerian Lingkungan Hidup dan Kehutanan. 2018. Status Hutan dan Kehutanan Indonesia 2018. Jakarta: KLHK.

[KLHK] Kementerian Lingkungan Hidup dan Kehutanan. 2019. Peran KPH dalam program perhutanan sosial [Makalah]. Disampaikan pada rapat koordinasi nasional KPH 2019. Yogyakarta: KLHK.

[KPK] Komisi Pemberantasan Korupsi. 2013. Nota Kesepakatan dan Rencana Aksi Bersama Percepatan Pengukuhan Kawasan Hutan. Jakarta: KPK.

Kuswidanti. 2008. Gambaran kemitraan lintas sektoral dan organisasi di bidang kesehatan dalam upaya penanganan flu burung di bidang komunikasi komite nasional flu burung dan pandemi influenza (Komnas FBPI) [skripsi]. Depok: Universitas Indonesia.

Mukarom M. 2013. Kemajuan dan upaya penanganan masalah tenurial di KPH Lindung Rinjani Barat [Makalah]. Disampaikan pada rapat koordinasi fasilitasi dan mediasi permasalahan tenurial di KPHL Rinjani Barat. Mataram: Dinas Kehutanan Provinsi Nusa Tenggara Barat.

Mustafa. 2002. Dinamika konflik dan model institusi pengelolaan kawasan yang berkelanjutan. Studi kasus pada pengelolaan kawasan konservasi Taman Nasional Meru Betiri, Jawa Timur [tesis]. Bogor: Institut Pertanian Bogor.

Riggs RA, Sayer J, Margules C, Boedhihartono AK, Langston JD, Sutanto. 2016. Forest tenure and conflict in Indonesia: contested rights in Rempek Village, Lombok. Land use policy. 57 (2016):241249.

Riski P. 2016. Skema kemitraan yang membuat warga desa rempek tersenyum [Internet]. [diunduh 2017 September 7]. Tersedia pada: http://www.mongabay.co.id/2016/01/04/skemakemitraan-yang-membuat-warga-desa-rempektersenyum/

Savath V, Fletschner D, Peterman A, Santos F, 2014. Land, Assets, and Livelihoods: Gendered Analysis of Evidence from Odisha State in India. Washington DC: International Food Policy Research Institute.

Schlager E, Ostrom E. 1992. Property-rights regimes and natural resources: a conceptual analysis. Land economics. 68(3):249-262.

Suryapriadi YE. 2013. Kontribusi kemampuan kerja dan motivasi berprestasi terhadap kinerja kpd tata 
usaha di SMP Negeri 5 Kota Bandung [skripsi]. Bandung: Universitas Pendidikan Indonesia.

World Bank. 2014. Towards Indonesian Land Reforms:

Challenges and Opportunities. A Review of the
Land Sector (Forest and Non-forest) in Indonesia. Jakarta: World Bank 